2019-06-30

\title{
Morphological divergence and reduced ectoparasite prevalence in an introduced population of a Caribbean anole
}

\section{Bodden, $\mathrm{V}$}

http://hdl.handle.net/10026.1/13333

\subsection{1/jzo.12664}

Journal of Zoology

Wiley

All content in PEARL is protected by copyright law. Author manuscripts are made available in accordance with publisher policies. Please cite only the published version using the details provided on the item record or document. In the absence of an open licence (e.g. Creative Commons), permissions for further reuse of content should be sought from the publisher or author. 
4

\section{Morphological divergence and reduced ectoparasite prevalence in an}

\section{introduced population of a Caribbean anole}

\section{Vaughn Bodden $^{1} \quad$ Robert Puschendorf ${ }^{1}$}

${ }^{1}$ School of Biological and Marine Sciences, Plymouth University, Plymouth, PL4 8AA, UK

Corresponding author- Email: vaughnbodden@gmail.com

\section{$\underline{\text { Abstract }}$}

Invasive species are characterized as effective dispersers, allowing them to rapidly colonize an area shortly after being introduced. As biological invasions become increasingly common understanding what factors drive a species' ability to rapidly colonize new habitats will be important for future conservation management. Theoretical models predict that spatial sorting of an invasive population will select for enhanced dispersal-related traits and lower prevalence of parasitic infections of individuals on the vanguard of range expansion when compared to those of the core population. In support of the models, there is a growing body of evidence that demonstrates both features are common in invasive populations, although, these observations stem from mainland systems, over larger spatial scales. Here we investigated the morphology and ectoparasite prevalence of Maynard's anole (Anolis maynardi) in its native range Little Cayman, and across its introduced range Cayman Brac where it was discovered 31 years ago. We tested for morphological divergence, ectoparasite prevalence, and the effects of parasite load on body condition between the native population and the core, intermediate and range edge populations within the introduced range. Our results suggest that spatial sorting could have selected for decreased ectoparasite prevalence on the range edge of the introduced population, across an area of just $39 \mathrm{~km}^{2}$. However, there was no difference in hind-limb length, the character that is expected to enhance dispersal ability, across the range of the introduced 

population. Instead, the greatest variation in morphology across the introduced range was found in

2 fore-limb length. Finally, both males and females from the introduced population were of

3 significantly higher body condition than the native population, yet ectoparasite intensity had no

4 effect on the body condition of infested hosts. These results highlight the rapid change of forelimb

5 length and a reduction in parasite prevalence on the range edge of the introduced population, together

6 these attributes have likely contributed to the successful colonization of Cayman Brac by $A$.

7 maynardi.

8

9 Keywords: Anolis maynardi; Trombiculid mite; Little Cayman; scaled-mass index; spatial sorting; 10 invasive species.

\section{Introduction}

Rapid spatial expansion into a new range is characteristic of a successful invasive species (Sakai et al., 2001). This behaviour is characterized by dispersal, the non-returning movement of an animal over time that has the potential to generate gene flow across space (Elton, 1958; Ronce, 2007). For invasive populations, natural variation in dispersal ability will determine which individuals drive the range expansion (Phillips, Brown, \& Shine, 2010a). Thus, the potential mates for an animal on the vanguard will also be determined by dispersal ability and, if the traits are heritable, their offspring will have similar characteristics (Phillips et al., 2008; Chuang \& Peterson, 2016). This spatial selection allows for traits advantageous for dispersal to accumulate on the range edge and can drive an increase in the rate of range expansion (Perkins et al., 2013). Comparatively, in core populations the selection for local adaptation outweighs that for dispersal and the frequency of dispersal related traits decrease (Phillips et al., 2010a; Perkins et al., 2013). Therefore, phenotypic signatures of this 
process should be evident between core and range edge populations of a species' range expanding through space (i.e. invasive populations).

4 Similarly, range expansion of a population can drive negative clines in parasite prevalence on the expanding front due to sub-sampling from core populations, lower transmission rates via reduced density-dependent interactions on the vanguard and the lowered dispersal ability of parasitized hosts from core populations (Torchin et al., 2003; Phillips et al., 2010b). The direct and indirect effects of parasitic infection for a host, such as impaired competitive or anti-predator behaviors, can have

9 detrimental fitness cost for an individual (Hatcher, Dick, \& Dunn, 2003; Lin et al., 2014).

Consequently, the net-negative effects can then be a limiting factor on population fitness, indeed, the success of many invasive species has been attributed to the loss of parasites (Dunn et al., 2012; Watson, 2013). Lower rates of parasitism among vanguard individuals can allow resources that would otherwise be used for immunity to be re-directed for activities such as movement and foraging, enhancing the fitness of vanguard populations (Phillips et al., 2010b; Chuang and Peterson, 2016). The enhanced viability of vanguard populations presents conservation managers tasked with controlling the spread of an invasive population with 'moving targets' and makes predicting the rate and extent of range expansion challenging to forecast (Campbell and Echternacht, 2003; Phillips et al., 2010b)

These two traits, morphological divergence and loss of parasites, can be thought of as indicators of a dispersal phenotype, because as a population expands its range the selection for these traits is more pronounced on the vanguard (Phillips et al., 2010b; Perkins et al., 2013). There is a growing number of biological invasions where spatial selection for a dispersal phenotype on the expanding front has been demonstrated. Morphological divergence of dispersal-related traits in vanguard populations has been observed in amphibians, for example in Australia with the invasive cane toad (Rhinella marina) 

and in France with the invasive African clawed frog (Xenopus laevis) (Phillips et al., 2006; Louppe et al., 2017). Similarly, reduced parasite prevalence in range-edge populations has been demonstrated with the blue striped snapper (Lutjanus kasmira) in Hawaii and the common house geckos (Hemidactylus frenatus) in Australia. In both cases there is a clear decrease in parasite prevalence moving from core, intermediate, to range-edge populations (Gaither et al., 2013; Coates et al., 2017).

6 In the examples for both, parasite loss and enhancement of dispersal related traits, these processes have mostly been observed within mainland systems at large spatial scales, whether spatial selection results in similar trends on small islands systems in much more confined systems has yet to be

9 investigated.

In this study we investigated Maynard's Anole (Anolis maynardi), an arboreal lizard that is native to Little Cayman, a small island $\left(26 \mathrm{~km}^{2}\right)$ within the Cayman Islands (Garman, 1888). The species was first discovered to be introduced on the nearby island of Cayman Brac $\left(39 \mathrm{~km}^{2}\right)$ in 1987 , near the airstrip on the west end of the island (Franz, Morgan, \& Davies, 1987). Then, a 2009 survey found

the introduced population had become abundant in the central forest area of the island and had diverged from the native population in traits such as tibia and radius length, but morphological differences could not be clearly explained by differences in habitat use (Herrel et al., 2011). The aim of our study was to investigate whether indicators of spatial selection dynamics (i.e. dispersal related traits) could be observed on the range edge of A. maynardi's invasion of Cayman Brac. Additionally, we document ectoparasite presence to compare prevalence of ectoparasites between native, core, and range edge populations to see if spatial sorting has resulted in a reduction in parasite prevalence on the range edge. Finally, the impact of ectoparasite infestation on host's body condition was investigated to test if any reduction in parasite load had given the introduced population a fitness advantage. We look at these two traits, morphological differences and parasite prevalence, between core and range edge populations as indicators of spatial sorting within an invasive population and 
therefore assess whether the process of spatial sorting in a range expanding population can be observed across small spatial scales in an island system.

\section{Methods}

$8 \quad$ Field sites

A. maynardi were sampled in 2017 in the introduced range Cayman Brac (July 2-16) and in the native range Little Cayman (July 18 -24). Daily sampling was conducted between 8:00 -18:00 at sites

12 in coastal scrublands and dry forest habitats, spaced roughly two kilometers apart. Global positioning coordinates were recorded for every individual (Figure 1) and used to classify individuals according to their capture sites. Individuals were categorized as belonging to these four populations: Little Cayman (Native) and within $6 \mathrm{~km}$ (Core), $12 \mathrm{Km}$ (Intermediate), or $18 \mathrm{Km}$ (Range edge) from the introduction point on Cayman Brac. These three sub-populations from Cayman Brac are hereafter

17 referred to as 'dispersal groups'.

$21 \quad$ Field data collection

All individuals were captured by hand or noose. An infrared thermometer was used immediately after to record body temperature, taken on the ventral side of each animal and perch temperature to the nearest $0.1{ }^{\circ} \mathrm{C}$ (Rowley \& Alford, 2007). For every captured individual the following habitat use 
characteristics were recorded: perch height, perch diameter and distance to nearest tree $>1 \mathrm{~m}$ in height.

Morphological characteristics were measured using digital calipers to the nearest $0.01 \mathrm{~mm}$ and mass was determined by weighing with a digital scale to the nearest 0.01 gram. For each individual the following morphological characteristics were recorded, snout-vent length (SVL), head width, head depth, head length, humerus length, radius length, metacarpal length, longest-toe forelimb, femur length, tibia length, metatarsal length, and longest-toe hindlimb. The sex of each lizard was determined by the presence of secondary sexual characteristics (e.g. post cloacal scales). Only adult lizards were used for analysis, the cut off size for mature females was $>45 \mathrm{~mm} \mathrm{SVL}$ and for adult males, the presence of enlarged tail base, large dewlap area, and a minimum of $>50 \mathrm{~mm}$ SVL was used to determine maturity (Lovern, Holmes, \& Wade, 2004). All measurements were taken on the right side of each animal by VB. From these morphological characters three additional variables were calculated: total forelimb length, total hindlimb length and body condition. The scaled-mass index (SMI) was used as an estimate of body condition because this method allows for relative comparisons between populations and sexes that have different mass/length relationships (Peig and Green, 2010). This is accomplished by standardizing to the mean SVL and including a scaling component that accounts for the non-linear relationships between mass and length across populations and sexes (Peig and Green, 2009). The natural logarithm of mass and SVL was used in the formula: $\mathrm{SMI} i=\mathrm{M} i(\mathrm{~L} 0 / \mathrm{L} i)^{\mathrm{bSMA}}$, where $\mathrm{M} i$ is the body mass of individual $i, \mathrm{~L}_{0}$ is the mean of SVL for the sample, $\mathrm{L} i$ is the SVL for individual $i$, bSMA is the scaling exponent calculated by taking the slope of a standardized major axis regression of mass on length, and SMI $i$ is the standardized body condition of individual $i$ (Peig and Green, 2009). The scaling component was calculated using the 'smatr' R package (Warton \& Ormerod, 2007). 
1 Finally, a hand lens (10x), was used to carefully inspect every individual for ectoparasites presence,

2 which was then used to calculate ectoparasite intensity (the number of mites per host) and ectoparasite prevalence (the number of infested individuals in the population). For the purposes of this study, parasites were identified to the family level as larval Trombiculidae spp. and ruled out as larval Amblyomma torrei, a known reptile tick found in the Cayman Islands, based on morphological features such as the gnathosoma characteristics, lack of dorsal scutum, and lack of festoons (Whittick, 1939; Shatrov \& Kudryashova, 2006).

\section{$\underline{\text { Statistical analysis }}$}

Prior to analysis, all morphological and habitat use variables were natural log transformed to meet assumptions of normality and homoscedasticity in the linear models. Only males $(n=42)$ were used in the morphological comparisons between dispersal groups because the small sample size between dispersal groups for females $(n=12)$ precluded statistical analysis. Size correction for the morphological variables used in the linear models and PCA analysis was done by taking the residuals from a linear regression of each variable against SVL.

Initial comparisons of morphology between male lizards from each island was done using a principal component analysis (PCA) for all size corrected morphological characters as loading variables except for total forelimb and hindlimb lengths, as they were represented by their individual segments. Next, a series of linear regressions were used to further investigate whether habitat use and morphology differed between native and introduced populations. Separate linear models were used to compare each of the three habitat use variables, the two temperature variables, the overall body size (SVL), and limb lengths for each island. 
2 To specifically address whether dispersal related traits differed between dispersal groups within the

3 introduced range, separate linear regressions were built for total forelimb and hindlimb length as

4 dependent variables. The explanatory variables included in the models were perch diameter, perch

5 height, distance to nearest perch, and dispersal group as independent variables. Explanatory variables

6 were dropped based on likelihood ratio test until a final simplified model was used for each trait

7 (Crawley, 2007). Quantile Quantile plots were visually inspected to confirm the assumptions of

8 normality and a Levene's test was used to confirm homogeneity of variance for each linear model.

10 Variables influencing ectoparasite prevalence were tested using a generalized linear model (GLM)

11 fitted with a binomial distribution and a logistic link function. Next, parasite prevalence was added as the response variable and the following explanatory variables were added : island, sex, habitat type, body condition, and an interaction between body condition and island. In a separate model, the parasite intensity data consisted of non-negative integer counts with a high proportion of zeros and few hosts with high intensities, so to analyze factors predicting parasite intensity per host, a GLM was fitted with a negative binomial distribution, a log link, parasite intensity as the response variable, and the same set of explanatory variables used for the prevalence model.

For the binomial and negative binomial regressions, explanatory variables were dropped from the final model based on examining null vs. deviance residuals and likelihood ratio tests. Body condition was then compared between each sex from two populations and between males in the dispersal groups from the introduced population using separate linear models. 
1 All statistical analysis was performed in R version 3.4.1 using the 'factoextra', 'ggplot2', 'MASS', and 'msme' packages (Venebles \& Ripley, 2002; Wickham, 2009; Hilbe \& Robinson, 2014; Kassambara \& Mundt, 2016; R Core Team, 2017).

\section{$\underline{\text { Results }}$}

\section{$\underline{\text { Habitat use and morphology between native and introduced populations }}$}

Males from the introduced population were found in habitats with a greater distance to nearest perch $\left(\mathrm{F}_{1 / 89}=5.739, \mathrm{p}=0.018\right)$, but showed no differences in the other habitat use characteristics: perch height $\left(\mathrm{F}_{1 / 89}=2.606, \mathrm{p}=0.11\right.$, perch diameter $\left(\mathrm{F}_{1 / 89}=0.238, \mathrm{p}=0.626\right)$, perch temperature $\left(\mathrm{F}_{1 / 89}=\right.$ $1.938, \mathrm{p}=0.167)$, and body temperature $\left(\mathrm{F}_{1 / 89}=1.184 ; \mathrm{p}=0.279\right)$. Males from the coastal shrub habitats used broader perches $\left(\mathrm{F}_{1 / 89}=8.099, \mathrm{p}=0.005\right)$ that had a greater distance to the nearest tree $>1$ meter $\left(\mathrm{F}_{1 / 89}=23.312, \mathrm{p}=<0.001\right)$, when compared to those in the dry forest but did not differ in perch height $\left(\mathrm{F}_{1 / 89}=0.726, \mathrm{p}=0.396\right)$. In addition, forelimb and hindlimb lengths did not vary significantly between the two habitat types $\left(\mathrm{F}_{1 / 89}=1.164, \mathrm{p}=0.283 ; \mathrm{F}_{1 / 89}=1.164, \mathrm{p}=0.283\right.$, respectively).

Most of the variation (43\%) in male A. maynardi morphology from each island was explained with similar positive loading values for all variables in PC1 except for tibia and metatarsal, which explained the remaining variation in PC2 (14\%) (Table 1). Males from Cayman Brac showed a large variation in morphology around each principal component axis, while males from Little Cayman showed little variation and were mostly nested within the ellipse of the introduced population (Figure 2). 
2 Males from each island (native vs. introduced) were not distinguishable by overall body size (SVL)

$3 \quad\left(F_{1 / 89}=2.103, p=0.141\right)$. For morphometric means and standard errors of each sex for both islands

4 see Appendix I. Forelimb and hindlimb lengths were greater for males from the introduced

5 population when compared to the native one $\left(\mathrm{F}_{1 / 88}=64.56, \mathrm{p}=<0.001 ; \mathrm{F}_{1 / 88}=33.27, \mathrm{p}=<0.001\right.$,

6 respectively). However, forelimb and hindlimb lengths were not correlated to log distance to nearest

7 tree, which is the only habitat use characteristics that they differed in $(\mathrm{df}=89, \mathrm{r}=0.05, \mathrm{p}=0.62 ; \mathrm{df}$

$8=89, \mathrm{r}=0.04, \mathrm{p}=0.64$, respectively).

9

10

11

12

13

$\underline{\text { Habitat use and morphology comparisons between dispersal groups within introduced population }}$

Within the introduced population, males from each dispersal group (core, intermediate, and range edge) were found to use the habitat in similar ways, we found no differences in the lizards' perch height $\left(\mathrm{F}_{2 / 39}=0.061, \mathrm{p}=0.941\right)$, perch diameter $\left(\mathrm{F}_{2 / 39}=0.592, \mathrm{p}=0.558\right)$, or distance to nearest tree $\left(F_{2 / 39}=0.452, p=0.639\right)$. Similarly, snout-vent-length and hindlimb length did not differ between dispersal groups $\left(\mathrm{F}_{2 / 39}=0.352, \mathrm{p}=0.705 ;\left(\mathrm{F}_{2 / 38}=1.496, \mathrm{p}=0.237\right.\right.$, respectively $)$. However, forelimb length increased with distance from introduction point $\left(F_{2 / 39}=7.337, p=0.002\right)$ (Figure 3). Perch diameter use explained a significant amount of variation in the hindlimb lengths between dispersal groups and was kept as a covariate in the linear model $\left(\mathrm{F}_{1 / 38}=7.472, \mathrm{p}=0.009\right)$. 
1 Ectoparasite prevalence was 30\% higher in the native population compared to the introduced population of $A$. maynardi (Table 2). Furthermore, within the introduced population all parasitized animals were found in the core and intermediate dispersal groups, while animals from range edge population were unparasitized (Figure 4). Finally, individual body condition was not a predictor of parasite prevalence or intensity (Table 2). However, lizards from the introduced population had significantly higher body condition than con-specifics from the native range for each sex (Males: $\mathrm{F}_{1 / 89}=17.677, \mathrm{p}=<0.001 ;$ Females: $\mathrm{F}_{1 / 24}=4.834, \mathrm{p}=0.038 ;$ Figure 5).

\section{$\underline{\text { Discussion }}$}

Our data reveals two key findings, firstly, male anoles from the range edge population have significantly longer forelimbs than both conspecifics from the native population and the core introduced group, surprisingly hindlimb length between dispersal groups did not differ (Figure 3). compared to the native population (Table 3; Appendix II). Furthermore, there was a clear reduction further research.

This increase in relative forelimb length towards the range edge is independent of measured differences in the habitat use characteristics. Secondly, both male and female anoles from the introduced population have significantly lower rates of Trombiculid mite prevalence and intensity in ectoparasite prevalence with distance from core populations and towards the range edge on Cayman Brac where, on the range edge, no lizards were found to be parasitized (Figure 4). The lower ectoparasite prevalence on the range edge supports the hypothesis that spatial sorting for less parasitized individuals on the vanguard could have occurred during the current range expansion of $A$. maynardi across Cayman Brac, however the morphological evidence is more tenuous and requires further research. 
3 Forelimb length show a clear increasing trend between core and range edge populations, however

$4 \quad$ hindlimb length has clearly been linked to dispersal capability in anoles, measured by sprint speeds

5 and jumping capabilities and it did not vary across our dispersal groups (Toro et al., 2004; Irschick et

6 al., 2005). Forelimb and hindlimb function in arboreal environments is more complex than in terrestrial ones so there is the possibility that longer forelimbs could contribute to dispersal ability in arboreal species (Cartmill, 1985). However, this is speculative and further work is necessary to demonstrate if there is any mechanistic link between increased locomotor capabilities and longer forelimbs in complex arboreal environments.

Why forelimb length has shown greater divergence compared to hindlimb length between dispersal groups is not clear. Differences in relative limb lengths between anole populations are typically linked to adaptive differentiation to new habitats but this was not the case in our study (Losos et al., 1997; Losos et al., 2001). Habitat use was consistent between the native and introduced populations and between the dispersal groups in the introduced range, so therefore did not explain the substantial forelimb length divergence. The lizards' habitat use presented in this study are similar to that of Herrel et al. (2011), where distance to the nearest perch differed between the native and introduced population but did not clearly explain any of the differences in relative limb lengths. This implies that the morphological divergence observed in the introduced population is not a result of habitat use differences and that other mechanisms are driving the morphological variation observed.

Whether longer forelimbs are a heritable trait or not will be important for determining a mechanism for the variation seen in the introduced population. Genetic input from multiple source populations with varying phenotypes can drive morphological divergence of an introduced population, as seen in 
the large-scale range expansion of $A$. sagrei across Florida (Kolbe, Larson, \& Losos, 2007). In contrast, the introduction of $A$. maynardi is rather simple, it has a single source population and has expanded through a relatively homogeneous landscape of dry forest and coastal scrublands (Herrel et al., 2011). Although multiple introductions of A. maynardi to Cayman Brac cannot be ruled out, the single source population does not appear to have the variation in limb lengths seen across males from the introduced population (Figure 3). Alternatively, anolis lizards raised in differing structural habitats (e.g. different perch widths) have been shown to exhibit substantial phenotypic plasticity in limb and toepad characteristics (Losos et al., 2000; Losos \& Kolbe, 2005). Slight variation in habitat structure across the island could result in the plastic response in limb length growth. Future genetic comparisons of the two populations and common garden experiments will be necessary to rule out that the morphological divergence seen in the introduced population is not a result of founder effects of phenotypic plasticity.

\section{$\underline{\text { Reduced parasite prevalence on the range edge of the introduced population }}$}

Our results support that the reduction of parasites prevalence is a common feature of non-native populations on their range edges (Torchin et al., 2003; Phillips et al., 2010b). What is not always clear is how or if reduced ectoparasite prevalence contributes to the success of an introduced species (Colautti et al., 2004; Prenter et al., 2004). In the case of A. maynardi, mite infestation had a negligible effect on body condition (Table 2), other studies have also highlighted an asymptomatic effect of ectoparasites in a range of reptile species based on body condition indices (Conover et al., 2015; Mayer et al., 2015; Barnett et al., 2018). However, body condition indices can only detect 
major differences in energy reserves between infested and non-infested individuals (Peig \& Green, 2009). Parasites have been shown to effect reptiles in less obvious ways such as, reducing the quality of sexual displays (Cook, Murphy, \& Johnson, 2013), negatively impacting movement and home range size (Main \& Bull, 2000), and enhancing immunocompetence (Spence et al., 2017) which all affect the success of invading individuals or populations in complex ways. More detailed measures of host fitness are needed to assess whether the reduced parasite prevalence has benefited $A$. maynardi in its introduced range.

Furthermore, $A$. maynardi is host to five species of nematode, although, endoparasite prevalence was not investigated in this study, it is possible that a combined reduction in the prevalence of all parasites could better explain differences in host body condition (Goldberg \& Bursey, 1996; Johnson $\&$ Hoverman, 2012). Nematodes found in vital organs can cause direct mechanical damage and thus have direct impact on host health, as seen in cane toads (R. marina) in Australia, where infection by a lung nematode directly impacted growth rates across all life stages, likely causing long-term fitness consequences (Kelehear, Brown, \& Shine, 2011). Future research should investigate what role, if any, endoparasite infection has in the successful establishment of A. maynardi in Cayman Brac.

Despite ectoparasite prevalence or intensity having no effect on body condition, animals from both sexes had a higher body condition in the introduced range. The differences in condition could potentially be the combined effect of parasite loss, reduced competition, and ecological release into a previously unoccupied arboreal niche across Cayman Brac which would provide access to more resources and positively impact individual body condition (Colautti et al., 2004; Dlugosch et al., 2015). Having larger energy stores is beneficial on the invasion front as it can assist with finding mates in low density situations and counteract costs associated with dispersal (Bonte et al., 2012). 
1 Together the increased body condition and reduced parasite load are likely factors that have contributed to the successful colonization of Cayman Brac by A. maynardi.

\section{Conclusion}

6 The results highlight substantial variation in forelimb length, and the overall morphology, of male

7 lizards within the introduced population of A. maynardi. . More importantly these differences may

8 have evolved over only 30 years since its first introduction in 1987 in an island only $38 \mathrm{~km}^{2}$.

9 Furthermore, Trombiculid mite prevalence was dramatically reduced in the introduced population and no infested individuals were found on the invasion range edge. . It is unknown whether the mites found on both islands are the same species, was co-introduced, or invasive to both islands, as they were morphologically indistinguishable and there are no taxonomic records for a Trombiculid spp. in the Cayman Islands (Hounsome, 1994).

Hereby we present information that documents $A$. maynardi's expanded range and morphological variation across Cayman Brac and the first investigation into ectoparasites affecting the species. The mechanisms for the increased forelimb length observed in the introduced population are not clear and future research is needed, including genetic testing, common-garden experiments, and additional female samples, to explain why the introduced population exhibits a substantially wider variation in forelimb length and overall morphology than found in the native population. Typically observed in mainland invasions, spatial selection dynamics have been shown in this study to select for a reduced ectoparasite prevalence in a small island system where it can positively influence the establishment and viability of an introduced species.

\section{Acknowledgments}


1 We would like to thank the Department of Environment of the Cayman Islands for granting the

2 research permit. Additionally, many thanks to Miguel Franco, Caroline Palmer, and the two

3 anonymous reviewers for helpful comments that enhanced the final version of this manuscript.

4

5

6

\section{$7 \quad$ Conflicts of Interest}

8 There are no conflicts of interest.

9

$10 \quad$ References

11 Barnett, L.K., Phillips, B.L., Heath, A.C., Coates, A. \& Hoskin, C.J. (2018). The impact of parasites

12 during range expansion of an invasive gecko. Parasitol., 1-10.

13 Bonte, D., Van Dyck, H., Bullock, J.M., Coulon, A., Delgado, M., Gibbs, M., Lehouck, V.,

14 Matthysen, E., Mustin, K., Saastamoinen, M. \& Schtickzelle, N. (2012). Costs of dispersal. Bio.

15 Revs., 87, 290-312.

16 Campbell, T.S. and Echternacht, A.C. (2003). Introduced species as moving targets: changes in body

17 sizes of introduced lizards following experimental introductions and historical invasions. Biol.

18 Invasions, 5, 193-212.

19 Cartmill, M. (1985). Climbing. In Functional Vertebrate Morphology (ed. M. Hildebrandt, D. M.

20 Bramble, K. F. Liem and D. B. Wake), 430. Cambridge: The Belknap Press of Harvard University

21 Press.

22 Chuang, A. \& Peterson, C.R. (2016). Expanding population edges: theories, traits, and trade-offs.

23 Glob. Chang. Biol., 22, 494-512. 
1 Coates, A., Barnett, L.K., Hoskin, C. \& Phillips, B.L. (2017). Living on the edge: parasite prevalence

2 changes dramatically across a range edge in an invasive gecko. Am. Nat., 189, 178-183.

3 Colautti, R. I., Ricciardi, A., Grigorovich, I. A. \& MacIsaac, H. J. (2004). Is invasion success

4 explained by the enemy release hypothesis?. Ecol. Lett., 7, 721-733.

5 Conover, A.E., Cook, E.G., Boronow, K.E. \& Muñoz, M.M. (2015). Effects of Ectoparasitism on

6 Behavioral Thermoregulation in the Tropical lizards Anolis cybotes (Squamata: Dactyloidae) and

7 Anolis armouri (Squamata: Dactyloidae). Breviora, 545, 1-13.

8 Cook, E.G., Murphy, T.G. \& Johnson, M.A. (2013). Colorful displays signal male quality in a 9 tropical anole lizard. Naturwissenschaften, 100, 993-996.

10 Crawley, M.J. (2007). The R Book, 1st edn. Imperial College London at Silkwood Park, UK: John 11 Wiley \& Sons Ltd.

12 Dlugosch, K.M., Cang, F.A., Barker, B.S., Andonian, K., Swope, S.M. and Rieseberg, L.H. (2015).

13 Evolution of invasiveness through increased resource use in a vacant niche. Nature plants, 1, 15066

14 Dunn, A.M., Torchin, M.E., Hatcher, M.J., Kotanen, P.M., Blumenthal, D.M., Byers, J.E., Coon, 15 C.A., Frankel, V.M., Holt, R.D., Hufbauer, R.A. \& Kanarek, A.R. (2012). Indirect effects of 16 parasites in invasions. Funct. Ecol., 26, 1262-1274.

17 Elton, C.S. (1958). The ecology of invasions by animals and plants. Methuen, London

18 Franz, R., Morgan, G.S. \& Davies, J.E. (1987). Some recent introductions of reptiles in the Cayman

19 Islands, West Indies. Herpetol. Rev., 18, 10-11. 
1 Gaither, M.R., Aeby, G., Vignon, M., Meguro, Y.I., Rigby, M., Runyon, C., Toonen, R.J., Wood,

2 C.L. \& Bowen, B.W. (2013). An invasive fish and the time-lagged spread of its parasite across the

3 Hawaiian Archipelago. PLoS One, 8, p.e56940.

4 Garman, S. (1888). Reptiles and batrachians from the Caymans and from the Bahamas. Collected by

5 Prof. C. J. Maynard for the Museum of Comparative Zoology at Cambridge, Mass. Bull. Essex Inst., $6 \quad 20,101-113$

7 Goldberg, S.R. \& Bursey, C.R. (1996). Anolis maynardi (ncn). Endoparasites. Herpetol. Rev., $27,19$.

8 Hatcher, M.J., Dick, J.T. \& Dunn, A.M. (2006). How parasites affect interactions between 9 competitors and predators. Ecol. Lett., 9, 1253-1271.

10 Herrel, A., Cottam, M.D., Godbeer, K., Sanger, T. \& Losos, J.B. (2011). An ecomorphological 11 analysis of native and introduced populations of the endemic lizard Anolis maynardi of the Cayman 12 Islands. Breviora, 1-10.

13 Hilbe, J., Robinson, A. \& Robinson, M.A. (2013). R Package 'msme'.

14 Hounsome, M.V. (1994). Terrestrial invertebrates (other than insects) of the Cayman Islands. In The 15 Cayman Islands (pp. 307-331). Dordrecht: Springer.

16 Irschick, D.J., Vanhooydonck, B., Herrel, A. \& Meyers, J.A.Y. (2005). Intraspecific correlations

17 among morphology, performance and habitat use within a green anole lizard (Anolis carolinensis) 18 population. Biol. J. Linn. Soc., 85, 211-221.

19 Johnson, P.T. \& Hoverman, J.T. (2012). Parasite diversity and coinfection determine pathogen 20 infection success and host fitness. Proc. Natl. Acad. Sci. U.S.A., 109, 9006-9011. 
1 Kassambara, A. \& Mundt, F. (2016). Factoextra: extract and visualize the results of multivariate data 2 analyses. $R$ package version, $1(3)$.

3 Kelehear, C., Brown, G.P. \& Shine, R. (2011). Influence of lung parasites on the growth rates of

4 free-ranging and captive adult cane toads. Oecologia, 165, 585-592.

5 Kolbe, J.J., Larson, A. and Losos, J.B. (2007). Differential admixture shapes morphological variation among invasive populations of the lizard Anolis sagrei. Molec. Ecol., 16, 1579-1591.

7 Kolbe, J.J. \& Losos, J.B. (2005). Hind-limb length plasticity in Anolis carolinensis. Journal of $8 \quad$ Herpetology, 674-678.

9 Lin, J.W., Lo, H.Y., Wang, H.C. and Shaner, P.J.L. (2014). The effects of mite parasitism on the reproduction and survival of the Taiwan field mice (Apodemus semotus). Zool. Stud., 53, 79.

11 Losos, J.B., Creer, D.A., Glossip, D., Goellner, R., Hampton, A., Roberts, G., Haskell, N., Taylor, P. 12 \& Ettling, J. (2000). Evolutionary implications of phenotypic plasticity in the hindlimb of the lizard 13 Anolis sagrei. Evolution, 54, 301-305. Losos, J.B., Schoener, T.W., Warheit, K.I. \& Creer, D. (2001). Experimental studies of adaptive differentiation in Bahamian Anolis lizards. In Microevolution Rate, Pattern, Process (pp. 399-415).

16 Dordrecht: Springer

17 Losos, J.B., Warheitt, K.I. \& Schoener, T.W. (1997). Adaptive differentiation following experimental island colonization in Anolis lizards. Nature, 387, 70.

19 Louppe, V., Courant, J. \& Herrel, A. (2017). Differences in mobility at the range edge of an 20 expanding invasive population of Xenopus laevis in the west of France. J. Exp. Bio., 220, 278-283. 
Lovern, M.B., Holmes, M.M. \& Wade, J. (2004). The green anole (Anolis carolinensis): a reptilian model for laboratory studies of reproductive morphology and behavior. ILAR J., 45, 54-64. Main, A.R. \& Bull, C.M. (2000). The impact of tick parasites on the behaviour of the lizard Tiliqua rugosa. Oecologia, 122, 574-581.

5 Mayer, M., Brown, G.P., Zimmermann, B. \& Shine, R. (2015). High infection intensities, but negligible fitness costs, suggest tolerance of gastrointestinal nematodes in a tropical snake. Austral.

$7 \quad$ Ecol., 40, 683-692.

8 Peig, J. \& Green, A.J. (2009). New perspectives for estimating body condition from mass/length 9 data: the scaled mass index as an alternative method. Oikos, 118, 1883-1891.

Peig, J. \& Green, A.J. (2010). The paradigm of body condition: a critical reappraisal of current methods based on mass and length. Funct. Ecol., 24, 1323-1332.

Perkins, A.T., Phillips, B.L., Baskett, M.L. \& Hastings, A. (2013). Evolution of dispersal and life history interact to drive accelerating spread of an invasive species. Ecol. Lett., 16, 1079-1087.

Phillips B. L., Brown G. P., Travis J. M. J. \& Shine R. (2008). Reid's paradox revisited: the evolution of dispersal kernels during range expansion. Am. Nat., 172, S34-S48.

Phillips, B.L., Brown, G.P. \& Shine, R. (2010a). Life-history evolution in range-shifting populations. Ecology, 91, 1617-1627.

Phillips, B.L., Brown, G.P., Webb, J.K. \& Shine, R. (2006). Invasion and the evolution of speed in toads. Nature, $\mathbf{4 3 9}, 803$.

20 Phillips, B.L., Kelehear, C., Pizzatto, L., Brown, G.P., Barton, D. \& Shine, R. (2010b). Parasites and pathogens lag behind their host during periods of host range advance. Ecology, 91, 872-881. 
1 Prenter, J., MacNeil, C., Dick, J.T. \& Dunn, A.M. 2004. Roles of parasites in animal invasions.

2 Trends Ecol. Evol., 19, 385-390.

3 R Core Team (2017). R: A language and environment for statistical computing. R Foundation for Sta

4 tistical Computing, Vienna, Austria.

5 Ronce, O. (2007). How does it feel to be like a rolling stone? Ten questions about dispersal

6 evolution. Annu. Rev. Ecol. Evol. Syst., 38, 231-253.

7 Rowley, J.J. \& Alford, R.A. (2007). Non-contact infrared thermometers can accurately measure 8 amphibian body temperatures. Herpetol. Rev., 38, 308-316.

9 Russell, A.P. \& Bels, V. (2001) Biomechanics and kinematics of limb-based locomotion in lizards: review, synthesis and prospectus. Comp. Biochem. Physiol. Part A, Mol. Integr. Physiol., 131, 89112.

12 Sakai, A.K., Allendorf, F.W., Holt, J.S., Lodge, D.M., Molofsky, J., With, K.A., Baughman, S., 13 Cabin, R.J., Cohen, J.E., Ellstrand, N.C. \& McCauley, D.E. (2001). The population biology of 14 invasive species. Annu. Rev. Ecol. Evol. Syst., 32, 305-332. Shatrov, A.B. \& Kudryashova, N.I. (2006). Taxonomy, life cycles and the origin of parasitism in trombiculid mites. Micromammals and macroparasites, 119-140, Springer, Tokyo. Spence, A.R., Durso, A.M., Smith, G.D., Skinner, H.M. \& French, S.S. (2017). Physiological Correlates of Multiple Parasitic Infections in Side-Blotched Lizards. Physiol. Biochem. Zool., 90, 321-327.

20 Torchin, M.E., Lafferty, K.D., Dobson, A.P., McKenzie, V.J. \& Kuris, A.M. (2003). Introduced species and their missing parasites. Nature, 421, 628. 
1 Toro, E., Herrel, A. and Irschick, D. (2004). The evolution of jumping performance in Caribbean

2 Anolis lizards: solutions to biomechanical trade-offs. Am. Nat., 163, 844-856.

3 Warton, D.I. \& Ormerod, J. (2007). R package 'smatr':(standardised) major axis estimation and

4 testing routines. GPL, CRAN, v 2.1 edition.

5 Watson, M.J. (2013). What drives population-level effects of parasites? Meta-analysis meets life-

6 history. Int. J. Parasitol. Parasites Wildl., 2, 190-196.

7 Whittick, R.J. (1939). On some ticks belonging to the genera Aponomma and

8 Amblyomma. Parasitology, 31, 434-441.

9 Wickham, H. (2016). ggplot2: elegant graphics for data analysis. Springer.

\section{Tables and legends}

12 Table 1. Loadings of the morphological variables in the PCA and the Eigenvalue of each component.

\begin{tabular}{lcc}
\hline Characters & PC1 & PC2 \\
\hline Head depth & 0.371 & -0.132 \\
\hline Head width & 0.285 & -0.222 \\
\hline Head length & 0.343 & -0.356 \\
\hline Humerus & 0.291 & 0.151 \\
\hline Radius & 0.368 & -0.148 \\
\hline Metacarpus & 0.296 & 0.117 \\
\hline Metacarpus IV & 0.311 & 0.024 \\
\hline Femur & 0.336 & 0.236 \\
\hline Tibia & 0.183 & 0.599
\end{tabular}




\begin{tabular}{lcc}
\hline Metatarsal & 0.115 & 0.554 \\
\hline Metatarsal IV & 0.310 & -0.160 \\
\hline
\end{tabular}

\begin{tabular}{lll} 
Eigenvalue & 2.171 & 1.252 \\
\hline \% variance explained & 0.429 & 0.142 \\
\hline
\end{tabular}

1 Table 2. Regression results from the GLMs for (a) parasite prevalence with a binomial distribution, a

2 logistic link function, and 113 degrees of freedom and (b) parasite load with a negative binomial

3 distribution, a logarithmic link function, and 113 degrees of freedom. For all chi- squared test the

4 degrees of freedom is equal to 1 . The parameter variable in brackets represents the factor used to test

5 against the null intercept. Bold p-values represent significance

\begin{tabular}{llcccccc}
\hline Model & Variable & \multicolumn{3}{c}{ Coefficients } & \multicolumn{2}{c}{ Chi-squared } \\
\hline & & Estimate & $\mathbf{2 . 5} \mathbf{~ C l}$ & $\mathbf{9 7 . 5} \% \mathbf{C l}$ & $\mathbf{P}$ - value & $\mathbf{X}^{\mathbf{2}}$ & P-value \\
\hline (a) & Island (LC) & 1.658 & 0.621 & 4.899 & $\mathbf{0 . 0 0 3}$ & 16.571 & $<\mathbf{0 . 0 0 1}$ \\
\cline { 2 - 8 } $\begin{array}{l}\text { Parasite } \\
\text { prevalence }\end{array}$ & Sex (Males) & 1.811 & 0.012 & 3.757 & 0.055 & 1.085 & 0.297 \\
\cline { 2 - 8 } & Body condition & -2.577 & -5.721 & 0.409 & 0.096 & 2.854 & 0.091 \\
\hline & & & & & & & \\
\hline (b) & Island (LC) & 2.186 & 0.924 & 3.541 & $<\mathbf{0 . 0 0 1}$ & 10.076 & $\mathbf{0 . 0 0 1}$ \\
\cline { 2 - 8 } $\begin{array}{l}\text { Parasite } \\
\text { intensity }\end{array}$ & Habitat (Forest) & 1.082 & 0.066 & 2.176 & $\mathbf{0 . 0 3 4}$ & 3.856 & $\mathbf{0 . 0 4 9}$ \\
\cline { 2 - 8 } & Body condition & 1.179 & -1.479 & 3.771 & 0.264 & 0.786 & 0.375 \\
\hline
\end{tabular}




\section{Figure legends}

1 Figure 1. Study area with location of animals used in this study as filled circles. 
1 Figure 2. Male A. maynardi points in morphological space of $\mathrm{PC} 1$ and $\mathrm{PC} 2$ for each population.

2 Loadings and importance of each principal component is listed in table 2. Around each population's 3 data points is a $95 \%$ confidence ellipse.

4 Figure 3. Total limb length (residuals) for male $A$. maynardi for the native population: $\mathrm{LC}(\mathrm{N}=49)$, 5 and each of the three dispersal groups from Cayman Brac: $\mathrm{CB}(6 \mathrm{Km})$ as the core population $(\mathrm{N}=$ $611), \mathrm{CB}(12 \mathrm{Km})$ as the intermediate population $(\mathrm{N}=16)$, and $\mathrm{CB}(18 \mathrm{Km})$ as the range edge

7 population $(\mathrm{N}=15)$. Pairwise ANOVA comparisons are presented for the groups within the Cayman

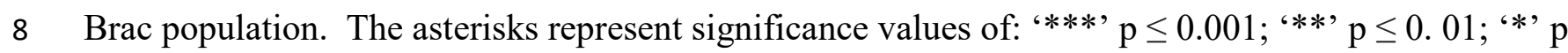
$9 \leq 0.05 ;$ ' $\mathrm{ns}$ ' $\mathrm{p}>0.05$.

11 Figure 4. Prevalence of Trombiculid mite infestation in A. maynardi for the native Little Cayman 12 population (LC) and each of the three dispersal groups on Cayman Brac, $\mathrm{CB}(6 \mathrm{Km})$ as the core; $\mathrm{CB}$ $13(12 \mathrm{Km})$ as the intermediate; and $\mathrm{CB}(18 \mathrm{Km})$ as the range edge, sample sizes: $\mathrm{N}=64,15,23$, and 16, respectively. For each population standard error bars around total prevalence are presented.

Figure 5. Estimates of body condition (scaled-mass index) for male and female $A$. maynardi from Little Cayman (native range) and Cayman Brac (introduced range). 


\section{Supplementary material}

Appendix I. Morphometric characterization of native (Little Cayman) and introduced (Cayman Brac) populations of Anolis maynardi.

\begin{tabular}{|c|c|c|c|c|}
\hline \multirow[t]{2}{*}{ Character } & \multicolumn{2}{|c|}{ Little Cayman } & \multicolumn{2}{|c|}{ Cayman Brac } \\
\hline & Males $(n=49)$ & Females $(n=14)$ & Males $(n=42)$ & Females $(n=12)$ \\
\hline SVL (mm) & $64.9 \pm 0.67$ & $49.0 \pm 0.39$ & $66.4 \pm 0.79$ & $49.3 \pm 0.62$ \\
\hline Weight (g) & $5.9 \pm 0.20$ & $2.9 \pm 0.09$ & $7.1 \pm 0.23$ & $3.2 \pm 0.09$ \\
\hline Head length (mm) & $21.3 \pm 0.27$ & $14.5 \pm 0.19$ & $22.9 \pm 0.34$ & $15.3 \pm 0.32$ \\
\hline Head width (mm) & $9.3 \pm 0.12$ & $6.9 \pm 0.06$ & $9.8 \pm 0.14$ & $7.2 \pm 0.09$ \\
\hline Head depth (mm) & $6.7 \pm 0.07$ & $5.2 \pm 0.09$ & $7.6 \pm 0.10$ & $5.7 \pm 0.09$ \\
\hline Humerus (mm) & $9.9 \pm 0.10$ & $7.6 \pm 0.10$ & $10.8 \pm 0.15$ & $7.9 \pm 0.08$ \\
\hline Radius (mm) & $8.1 \pm 0.08$ & $5.9 \pm 0.08$ & $8.8 \pm 0.10$ & $6.3 \pm 0.21$ \\
\hline Metacarpal (mm) & $2.6 \pm 0.03$ & $2.0 \pm 0.06$ & $3.1 \pm 0.06$ & $2.4 \pm 0.15$ \\
\hline Longest toe forelimb (mm) & $5.4 \pm 0.05$ & $3.9 \pm 0.09$ & $5.9 \pm 0.08$ & $4.2 \pm 0.13$ \\
\hline Forelimb (mm) & $26.1 \pm 0.22$ & $19.5 \pm 0.23$ & $28.7 \pm 0.31$ & $21.0 \pm 0.32$ \\
\hline Femur (mm) & $12.3 \pm 0.10$ & $9.3 \pm 0.09$ & $13.1 \pm 0.14$ & $9.6 \pm 0.14$ \\
\hline Tibia (mm) & $13.2 \pm 0.09$ & $10.0 \pm 0.06$ & $13.7 \pm 0.17$ & $9.9 \pm 0.21$ \\
\hline Metatarsal (mm) & $7.8 \pm 0.06$ & $5.9 \pm 0.09$ & $8.1 \pm 0.10$ & $5.7 \pm 0.17$ \\
\hline Longest-toe hindlimb (mm) & $9.7 \pm 0.10$ & $6.9 \pm 0.09$ & $10.5 \pm 0.13$ & $7.4 \pm 0.14$ \\
\hline Hindlimb (mm) & $42.9 \pm 0.30$ & $32.2 \pm 0.20$ & $45.4 \pm 0.42$ & $32.7 \pm 0.41$ \\
\hline
\end{tabular}

Table entries are means \pm standard errors. 
Appendix II. Characterization of parasitism by Trombiculid spp. on the native and introduced populations of A. maynardi. Lower and upper $95 \%$ confidence intervals $(\mathrm{Cl})$ for prevalence was calculated using the Wilson's score interval.

\begin{tabular}{ccccccc} 
Island & Sex & $\mathbf{n}$ & Prevalence (\%) & $\mathbf{2 . 5} \mathbf{~ C l}$ & $\mathbf{9 7 . 5} \mathbf{~ C l}$ & Mean intensity $^{\mathbf{2}}$ \\
\hline Little Cayman & Male & 49 & 43 & 30 & 56.7 & 4.8 \\
\cline { 2 - 7 } & Female & 14 & 35 & 16.3 & 61.2 & 8 \\
\hline Cayman Brac & Male & 42 & 12 & 5.2 & 25.1 & 4.6 \\
\cline { 2 - 7 } & Female & 12 & 0 & 0 & 0 & 0
\end{tabular}

${ }^{1}$ Number of infested individuals / number of individuals sampled.

${ }^{2}$ Mean intensity of ectoparasites per infested host. 